
AFRIKA

Die huidige situasie in die Afrika-gebiede Suid van die Sahara en Noord van die Limpopo ontwikkel in die rigting van die chaotiese. 'n Tydperk van betreklike rus, veiligheid en vrede is afgesluit en rewolusionêre magte is ontketen. Die haat van die massa is gerig teen die Blanke wie se koms in Afrika die einde beteken het van eindelose stamoorloë, slawehandel en pes en wie se beskawing nuwe, ongekende lewensmoontlikhede vir die destydse ,,donker Afrika" meegebring het.

Uit die Belgiese Kongo vertrek die Blanke tans haastig met soveel moontlik van sy beleggings terwyl die politieke leiers van die inboorlinge op die vooraand van die begeerde vrywording van die sogenaamde Blanke oorheersing in ' $n$ verbete stryd om politieke mag gewikkel is. In Kenia, Tanganjika, Nyassaland en Noord Rhodesië sit duisende besorgde Blankes en kyk na die spel tussen 'n onseker koloniale regering en opgeweepte Naturelle leiers. Hulle toekoms is in hierdie spel gemoeid. Terselfdertyd word miljoene van Afrika se swart inwoners hoe langer hoe meer uitgelewer aan die willekeur van hulle leiers, massamoord, intimidasie en uitbuiting.

Die huidige Afrika is die resultaat van die werking en interwerking van verskillende faktore en magte. Ons wil enkeles noem:

Die verwestering van Afrika:

Vir baie jare het Afrika alleen maar in die invloedssfeer van die westerse beskawing gestaan, en dit het oneindig veel bygedra tot die ontwikkeling en ontwaking van hierdie kontinent. Onder die positiewe bydraes van die Weste wat aanleiding gegee het tot die ontwikkeling van die huidige situasie, die volgende:

\title{
Kulturele bydraes:
}

Die belangrikste bydrae is hier seker die christelike godsdiens. Die Blanke het die christelike godsdiens, waar rondom sy beskawing gegroei het, ook aan die inboorlinge van Afrika probeer gee. Die swart man van Afrika is gekonfronteer met Christus en sy kultuur oopgestel vir bevrugting met ' $n$ christelike kultuur. Daarby het die sendelinge, en dan veral die protestantse sendelinge, 'n geweldige bydrae gelewer tot die oopstelling van Afrika. Hulle het dit gedoen onder die gevaar van tropiese siektes, vyandigheid van opperhoofde, bygeloof en dikwels onder meedoënlose wedywering met die mohammedanisme wat aanneemliker vir die Bantoetemperament is. Dit is sekerlik nie te veel gesê as beweer word dat die pogings tot kerstening van Afrika die belangrikste positiewe bydrae van die Weste is tot die ontwaking van Afrika. Daar is in Afrika alleen maar ongeveer 20 miljoen christene maar die invloed van die Christendom strek baie verder as net hierdie betreklike klein getal gelowiges. Die Christusverkondiging het vir die inboorlinge bevryding beteken van 'n 
oneindige klomp magte waaraan hy in sy Naturalisme gebonde was op so 'n wyse dat daar van vryheid by hom haas geen sprake kon wees nie. Die begrip vryheid is egter ook oorgeneem deur baie nie-gelowiges wat daaraan hulle eie vulling gegee het.

Aan die sendingsaksie was daar ook die onderwys gebonde. Dit het vinnig uitgegroei sodat daar aan die einde van 1954 reeds meer as 5 miljoen leerlinge was. Sekondêre skole en verskillende opleidingsentra vir onderwysers is gestig. Daar benewens het ongeveer 9,000 studente jaarliks aan oorsese universiteite gestudeer. Die westerse kultuur het verder sy invloed laat geld langs die weg van die radio, films en koerante.

\section{Maatskaplike bydraes:}

Die koms van die witman het beteken die beëindiging van stamoorloë wat vrede, veiligheid en verhoogde stoflike welvaart meegebring het. Slawehandel en kannibalisme is beëindig. Gesondheidsdienste en geneeskunde het gelei tot ' $n$ laer sterftesyfer en die fenomenale groei van bevolkingsgroepe.

\section{Ekonomiese bydraes:}

Die Blanke met sy verbeterde landbou en veeteelt, sy mynbou, industrieë, verkeer en handel het ekonomiese welvaart en nuwe bestaansmoontlikhede vir die inboorlinge geskep.

\section{Staatkundige bydraes:}

Die koloniale moondhede kan in twee groepe verdeel word: Eerstens die groep wie se begrip „kolonie” Rooms Katoliek ge-oriënteerd is. Hier kan ons noem Portugal, Frankryk en in 'n sekere opsig, België. In kolonies van hierdie lande is 'n Eur-Afrika-politieke-unie voorgestaan. Die kolonie is ' $n$ provinsie van die moederland waar die hoof regeringsmag gesentraliseer is. Die kolonie het sy verteenwoordiging op die sentrale regering. Ekonomies is die kolonie geïntergreer met die moederland. Daar word gestrewe na kulturele assimilasie.

Tweedens, die portestants ge-oriënteerde Britte. In die Britse kolonies word die inboorlinge doelbewus ingelei in die demokratiese regeringstelsel en na mate die inboorlinge vorder, word al groter deelname in die regering van die kolonies aan hulle gegee met die voorneme om uiteindelik selfregering aan die gebiede toe te staan. Dit is die beleid van „creative abdication". Die voorlaaste stadium in hierdie beleid is intergrasie op alle vlakke. Dit moet dien as oorgang, as brug tot selfregering. Die beleid is vir die doel in die koloniale kantoor ontwerp en in die gebiede vanuit die kantoor toegepas in die Federasie as "partnership" en in Kenia as „multiracialism”. Dit word egter nie onmiddellik eerlik deurgevoer nie, maar kom langsaam as toegewings onder druk. Hier is integrasie slegs 'n oorgangsbeleid. Die permanente is selfregering, en dit is noual voorsienbaar dat selfregering nie net beteken dat die koloniale regering vertrek nie, maar dat dit die teken vir die exodus van die Blankes 
is. Dit is wesenlik anders as in Suid-Afrika. Hier is die Blanke vasberade om te bly en integrasie word deur sy voorstanders hier bedoel as permanente oplossing teenoor aparte ontwikkeling.

Die verwestering van Afrika het die situasie waarin die inboorlinge verkeer het, radikaal verander. Hulle is gekonfronteer met dit wat vir hulle geheel en al nuut was en ingrypende veranderings in hulleself en hulle samelewing te weeg gebring het. Die kontak met die westerse kultuur was in baie opsigte voordelig en het bevrugtend op hulle eie kultuur ingewerk. Hulle is bevoordeel deur die maatskaplike en ekonomiese verbeterings wat die westerlinge onder hulle tot stand gebring het. Hulle het kennis gemaak met die westerse manier van administrasie en is ingelyf in die patroon en prosedure van die westerse staatkunde met sy partypolitiek en stemreg. Op hierdie wyse het die Weste bygedra tot die ontstaan van 'n nuwe, 'n verligte Afrika wat ander en blykbaar ook moeiliker probleme het as ",donker Afrika".

Maar nou het die Weste ook nog, behalwe dat sy kulturele bydraes ook soms ontwrigtend gewerk het, 'n negatiewe bydrae gelewer wat die tempo van ontwikkeling na die huidige situasie verskerp het. Die moderne mens van hierdie eeu hou eintlik nie meer rekening met God of afgod nie. Hy glo dat daar op die aarde net mense woon. Hierdie mense is goed, redelik en fatsoenlik. Uit homself kan al sy probleme benader en opgelos word. Vir hulle onderlinge verhouding is aan hulle ,unalienable rights: life, liberty and the pursuit of happiness"1) gegee.

Van uit hierdie beskouing dat daar op die aarde net mense woon wat almal gelyk is, mense met vaste omskrewe regte wie se probleme alleen uit die mens self opgeklaar kan word, verset die westerling hom tans teen elke vorm van kolonialisme, behalwe teen die moderne kolonialisme van Amerika. Daar word gemeen dat al Afrika se probleme verdwyn op die oomblik dat selfregering aan die gebiede in Afrika gegee is.

Amerika was die aanvanklike en venynigste kritikus. Daar is egter ook selfkritiek deur die koloniale moondhede beoefen en langsamerhand het daar by hulle 'n skuldkompleks ten opsigte van hulle kolonies ontstaan. Toe is daar begin boedel oorgee-en dit op 'n stadium waarin dit duidelik is dat die inboorlinge in die kolonies nog nie ryp is vir selfbeskikking nie. Ons wil hulle dit sekerlik gun, maar dan eers wanneer hulle in staat is om ordelik en verantwoordelik vrye volk te wees.

Die Kommunisme, en sedert die Bandungkonferensie ook die AfroAsiatiese Blok, het onmiddellik hierdie selfkritiek en skuldgevoel uitgebuit. Die koloniale moondhede is an die inboorlinge voorgehou as cnderdrukkers terwyl hulle self poseer as die bevryders wat die belange van die inboorlinge op die hart dra. Vir Rusland gaan dit om die mobilisasie van die miljoene van Afrika teen die Weste. Rooi Sjina en Indië is op soek na lewensruimte vir hulle oorbevolkings.

Hierdie emosionele benadering van Afrika, tesame met die kram-

1) Amerkikaanse Onaf hanklikheidsverklaring 1776, 
pagtige vrees dat Afrika pro-kommunisties of kommunisities sal word, is na ons mening een van die vernaamste redes vir die oorhaastige vertrek van die koloniale regerings uit Afrika. In samehang met die agtergrond van sekere Afrika-leiers lyk dit juis asof hierdie gebeurtenis die betrokke gebiede in Afrika in die skoot van die kommunisme soos ryp vrugte laat val.

Hierdie benadering het ook aan die wêreld 'n verwronge perspektief oor Afrika gegee. Dit is tans dié plek in die wêreld waar die witman verdrukker en verontregter is. Maar die mees verwronge perspektief het aan gevolge van hierdie benadering juis in die harte van die inboorlinge self onstaan.

\section{Die rol van sekere inboorlingleiers in Afrika:}

Daar bestaan sekerlik nog nie so iets soos 'n Afrika-nasionalisme nie. Op die Accra-konferensie is die dringende behoefte aan 'n Afrika-siel gevoel wat die verskillende Afrika-volke kan saambind. Uit resente gebeure in kolonies in die bestrokke gebied blyk dit ook nie asof die begrip „nasionalisme” reg laat geskied aan die gebeure aldaar nie. Daar is geen saambindende faktore aanwesig onder die verskillende nieblanke volke van Kenia byvoorbeeld nie, behalwe die gemeenskaplike haat teen die Blanke en daarop kan geen nasionalisme gebou word wat die verskillende volke sal insluit nie. Daar word egter wel sterk volksnasionalisme aangetref. Die grense tussen Kikuyu en Masai is baie skerp. Dit is twee volke wat op kulturele en staatkundige gebied 'n minimum met mekaar gemeen het. Daar bestaan ook eeue oue vyandskap tussen verskillende van die volke wat selfs onder die regering van die koloniale moondhede van tyd tot tyd tot uitbarsting gekom het.

Nou bestaan daar egter in elke kolonie 'n groep wat hulle self as die intelligensia beskou en wat alles probeer doen om die volksnasionalisme van bepaalde volke in 'n gebied af te breek en hulle beywer vir 'n nasionalisme wat al die volke in die kolonie insluit. Die meeste van die sogenoemde intelligensia het gestudeer aan buitelandse universiteite of is die produkte van binnelandse onderwysinrigtings wat reeds 'n rewolusionêre gees adem. (So bv. die ,independant schools" van Peter Koinange en Jomo Kenjatta.) In die buiteland verkeer die studente onder vreemde invloede. Die Pan Africanist Congress en die kommuniste slaan veral hier toe. Negly Farson ${ }^{2}$ ) verklaar al in 1949 dat dit eintlik net die kommuniste is wat werklik belangstel in die meer as 900 nie-Blanke studente uit Afrika wat jaarliks in Londen studeer. Jomo Kenjatta was byvoorbeeld sewentien jaar lank in die buiteland. Hy het gestudeer in Londen (London School of Economics), Parys, Berlyn en hy was vir 'n onbekende aantal jare in Moskou waar hy tuisgegaan het in die Lux-hotel wat verblyfplek verskaf aan lede van die Komintern. Terug in Kenia was hy spoedig president van die „Kenya African Union” en organiseerder van die

2) Negley Farson, Last Chance in Africa, London, 1949, bl. 212. 
Mau Mau en is blykbaar na jare lange gevangenisskap nog die leier van sekere groepe in Kenia soos blyk uit die jongste agitasie van Tom Mboya en party genote om hom vrygelaat te kry. Verskillende van die leidende partyleiers in die Belgiese Kongo word van kommunisme verdink.

En nou is dit juis hierdie manne wat deur die wëreld gesien word as die leiers van Afrika. In werklikheid is hulle egter nie die natuurlike leiers van die Afrika-volke nie, maar hulle het die posisies bekom langs die weg van politieke organisasies_'n manier van doen wat aan die inboorling vreemd is.

Van Jomo Kenjatta sê Farson: ,Jomo Kenjatta's experience in Europe taught him something about the African, his weak points and how to handle him. But for whose benefit? That is the riddle of Jomo Kenjatta." ${ }^{3}$ ) Is dit nie die vraagteken wat agter baie Afrika-leiers se name geplaas moet word nie? Hulle organiseer stakings en veldtogte om wetsongehoorsaam te wees. Daarmee dompel hulle nie alleen die Blankes in 'n onseker situasie nie, maar dit bring ook ontwrigting, uitbuitery en intimidasie van die inboorlinge self met sig mee. Duisende van dié wat vir Jomo Kenjatta gevolg het, het gesterf, maar ook groot getalle van hulle wat hom nie wou volg nie is om die lewe gebring. In Ghana maak Nkurumah die opposisie stil deur hulle in tronke toe te sluit.

Die rol van die kommunisme in Afrika:

Daar is reeds gewys op die invloed van die kommunisme op sekere Afrika-leiers.

Rusland en Rooi Sjina stel intens belang in Afrika. Met Ghana se onafhanklikheidsvierings het Rusland visums gevra vir 'n afvaardiging van 116. Ingeligte bronne meen dat daar aan die einde van 1960 tien Russiese en 3 Rooi Sjinese ambassades in Afrika sal wees. In Addis Ababa hou Rusland 'n ambassade van tussen 300 en 800 in stand. Daarby kom nog ' $n$ inligtingskantoor en vry hospitalisasie. Die Kommunisme voer in Afrika soos elders die beleid van ekonomiese en politieke infiltrasie. Hulle tree ook nie self op die voorgrond nie maar maak gebruik van organisasies binne kolonies en selfstandige state om hulle doel vir hulle te verwesentlik. Die nasionalistiese strewes van inboorlingleiers word aangeblaas en hulp word verleen aan sekere politieke organisasies. 'n Oor en weer kuiery tussen Kroetschof en 'n paar Afrika-leiers is vir 1960 in die vooruitsig gestel.

Daagliks saai Rusland na Afrika in Frans, Engels en Kiswahili sy propaganda uit. Die 20ste kongres van die kommunistiese party het besluit om navorsing oor Afrika en effektiewe propagandamiddels vir die bevryding van Afrika te vehaas. Dit doen Rusland en Rooi Sjina nie omdat hulle so intens belangstel in die welsyn van die inboorlinge nie. Dit gaan vir Rusland om die mobilisasie van die miljoene van Afrika

$\left.{ }^{8}\right)$ Negley Farson, a.w., bl. 113. 
en sy onontginde rykdomme as middele om sy magsposisie teen die W'este te versterk.

So lê Afrika in die lig van die felste magstryd van baie eeue. Die swart man is skielik belangrik-ver belangriker as die paar miljoen Blankes. Daar word gewedyder om sy guns. Dr. Sala-Zar het onlangs gesê dat sonder Afrika by die Weste die kommunisme noual aan die vrye wêreld die voorwaardes vir sy voortbestaan kan voorskrywe. Tot nou toe het die Weste Afrika se guns probeer koop met selfregering, die belofte van selfregering en hulpverleningskemas. Daarteenoor het die kommunisme gestel nie alleen sy eie hulpverlening nie, maar ook 'n ideologie wat vir die inboorling in sy huidige staat van agterdog teenoor die Blanke die aanneemlike, ja selfs die ideale blyk te wees.

En nou beleef Afrika die uittog van die Blanke. Sy skouers is geboë onder die las van kritiek en skuldbesef. Bowendien dra hy die Kainsmerk: oneerlike verdrukker! Op Afrika bly daar egter 200 miljoen inboorlinge agter. Slegs tien persent van hulle is gekersten. Hulle is aan hulle self in hulle verdeeldheid en verwarring oorgelaat. Hulle is uitgelewer aan die willekeur van hulle leiers. In hulle huidige staat van ontwikkeling is hulle slegs ryp om die prooi te word van sataniese magte, wie se uitbuiting veel erger is as dié waaraan hulle voorouers onderworpe was voor die koms van die Blanke in Afrika.

Op hierdie gebeure in Afrika sal die kommentaar van die kerk, wat veel meer sal moet wees as net enkele kantaantekeninge, nie mag uitbly nie. Ons wil slegs op enkele dinge wys:

1. Eerstens sal die kerk homself rekenskap moet gee van die hegrip kolonie en o.a. sal daar vasgestel moet word wat die verantwoordelikheid van die koloniale moondheid teenoor die kolonie is. Ook sal daar vasgestel moet word of die hulpverleningskemas van Amerika en Rusland nie maar net 'n nuwe, maar meer subtiele metode van kolonisasie is nie, waarin weliswaar aan volke selfregering gebied word, maar verder is hulle afhanklik van die groot moondhede vir hulle beskerming en finansiële voortbestaan.

2. Tweedens sal die kerk blykbaar die oorhaastige vertrek van die koloniale moondhede uit Afrika om verskeie redes moet afkeur.

Dit blyk dat daar op die vertrek van die koloniale regering anargie, chaos en vernietiging volg. Maar nou het die kerk die staat nog altyd gesien as dienares van die God wat die chaos orden en die staat wil gebruik om dit te doen. In die staat moet iets sigbaar word van die vleeswording van die Woord van God waarin sy ewige lig onoorwinklik ingeslaan het in die duisternis. Die staat mag die chaos nie toelaat of deur sy eie optrede, gelei deur watter motiewe ookal, laat ontstaan nie. As sy vertrek uit sy eertydse kolonie anargie en chaos laat onstaan, is dit ' $n$ misdaad om te vertrek. 
Die uittog geskied blykbaar ook nie sonder selfsugtige motiewe nie. Het die verantwoordelikheid vir 'n moeiliker beheerbare. Afrika nie 'n te sware las vir die koloniale moondhede geword nie? Verder lê Afrika in die lig van 'n internasionale stryd om mag en gaan Afrika nou in die wedywering om sy guns nie miskien die lydende party wees nie?

3. Die Blanke regerings vertrek op grond van selfkritiek wat gebaseer is op 'n onbybelse voorveronderstelling naamlik dat daar op aarde slegs mense woon wie se probleme alleen vanuit die mens benader en opgelos kan word. Die Bybelse openbaringsbegrip sê juis: God het mens geword! $\mathrm{Hy}$ het nie vertrek nie, maar $\mathrm{Hy}$ is nou juis by ons. „Hij en wij zijn buren en vrienden."4) Afrika, Asië, Amerika en Europa is nie sonder God en sy genadige, vir die mense heilsame teenwoordigheid nie. Die mens en sy probleme is vanuit Christus, dié mens van God, alleen te benader en nie vanuit die mens self nie. Die eerste en die laaste woord oor Afrika is nie die Handves van die V. V. O. of die Amerikaanse Onafhanklikheidsverklaring nie, maar Jesus Christus.

4. Die kerk sal ook sy stem moet laat hoor nie net alleen teen die oorstroming van Afrika met die produkte van 'n heidense kultuur nie, maar ook teen die produkte van 'n gesekulariseerde christelike kultuur. Die produkte word, soos Berkhof ${ }^{5}$ ) dit sien, ingeënt op 'n volksliggaam wat hoofsaaklik naturalisties van aard is. Die boom waaraan hierdie vrugte moet groei is egter nouliks oorgeplant. Die gevolg is dat die mense wat met hierdie produkte oorstroom word, daardeur ontwortel word. Die positiewe agtergrond van die hulpverlening ontbreek, naamlik die konfrontasie met die Here. Die hulpverlening bring dan ekonomiese seën mee, maar terselfdertyd is dit verkragting van die gees van die ontvangers. Die hulpverleners is hiervan onbewus omdat hulle nie meer bewus is van die christelike voorveronderstellings van hulle eie kultuur nie. Dit kan lei tot een van twee dinge: of verwoestende nihilisme of 'n welbewuste vra na Christus. En as die laaste, as die enigste sinvolle moontlikheid in vervulling gaan, sal die kerk die Christusprediking met onge-ewenaarde erns moet aanpak.

Dit is duidelik dat die oorstroming van Afrika met die produkte van ons westerse kultuur alleen, Afrika nie sal kan red uit die kloue van die sataniese magte wat oor hom toesak of wat uit hom self groei nie. Hulpverlening is nie die woord wat die Weste in die hart van Afrika moet lê as die woord wat Afrika vir die woord van die kommunisme of die mohammedanisme geslote sal hou nie. Die. enigste woord wat dit kan doen is die Woord waaraan die Weste self arm is naamlik God se Woord. Die hulp van Afrika sal eerstens die verkondiging van hierdie Woord moet wees. En dit sal niks meer as net hierdie Woord moet wees wat verkondig word nie. Hierdie Woord het in die vrymagtigheid van die Heilige Gees tog sekerlik die vermoë om tot elke volk in sy

4) A. A. van Ruler, Visie en Vaart, Amsterdam, 1947, bl. 142.

5) H. Berkhof, Christus de Zin der geschiedenis, Nijkerk, 1958, bl. 90. 
situasie en in sy kultuur so te spreek dat daardie volk sal hoor en dan só sal hoor dat hy sy eie christendom sal vorm, 'n christendom wat in die dinge waarop dit aankom nie van ons s'n sal verskil nie, maar tog gekleed sal wees in die $A B C$, in die kleuring waarvan die Heilige Gees Hom onder daardie volk wil bedien.

C. J. Mans. 